\title{
Association between Preschool Children Nutrition and Cognitive Performance
}

\author{
Rania A.Bassuoni ${ }^{1}$, Laila Hussein ${ }^{1}$, Magda S.Mohamed ${ }^{1}$, Zeinab M. Monir ${ }^{2}$ and \\ Ashraf A.AbdEl-Megeid ${ }^{3}$
}

1Departments of Nutrition, National Research Center, Giza, Egypt 2Departments of Child Health National Research

Center, Giza, Egypt 3Department of Nutrition and Food Science, Helwan University, Cairo, Egypt

\begin{abstract}
The present study is aimed to assess the nutritional status and cognitive performances of some preschool children (57.2-71.39 months). The study was performed on 39 children $51 \%$ were girls and $49 \%$ were boys with a mean age of $53.59 \pm 1.85$ months. All children from cities Giza government. The obtained data showed that mean value body weight, height, body mass index (BMI), and mid upper arm circumference (MUAC) were $16.97 \pm 0.26 \mathrm{~kg}, 101.7 \pm 0.98 \mathrm{~cm}, 16.47 \pm 0.21 \mathrm{~kg} / \mathrm{m}^{2}$, and $14.01 \pm 0.33 \mathrm{~cm}$

respectively. According to the food intake analysis, the mean value intake of total energy, protein, fat, and carbohydrate was $985.08 \pm 32.79 \mathrm{kcal}, 33.74 \pm 1.12 \mathrm{~g}, 33.98 \pm 1.28 \mathrm{~g}$, and $110.96 \pm 3.89 \mathrm{~g}$ respectively. The mean value intake of some minerals (Iodine, Iron, Selenium, and Zinc) was $81.64 \pm 5.49 \mu \mathrm{g}, 9.71 \pm 0.49 \mathrm{mg}$, and $42.79 \pm 2.67 \mu \mathrm{g}$ and $4.77 \pm 0.22$ $\mathrm{mg}$ respectively. The mean value intake of some vitamins (Vitamin A, Vitamin B1, Vitamin B2, and Vitamin C) was $273.23 \pm 25.57$ I.U, $0.45 \pm 0.06 \mathrm{mg}, 0.49 \pm 0.03 \mathrm{mg}$, and $17.01 \pm 1.14 \mathrm{mg}$ respectively. Some biochemical analyses showed that the mean value urinary iodine was $159.55 \pm 3.08 \mu \mathrm{g} / \mathrm{l}$, and blood hemoglobin was $11.5 \pm 0.10 \mathrm{~g} / \mathrm{dl}$. The Wechsler tests were done to calculate student IQ, the mean value of verbal IQ was $103.23 \pm 1.18$, the mean average of performance IQ was $76.23 \pm 2.78$, and the mean of total IQ was $94.61 \pm 0.93$. Finally, this study is importance due to the lack of studies in this stage of childhood and so we recommended that to more investigation need to done at this stage of childhood especially with the increasing interest of the Egyptian government in the healthy nutrition of children.
\end{abstract}

Key words: Nutrient intake, IQ children, Early childhood stage , Preschool children 


\section{$\underline{\text { Introduction }}$}

Early childhood constitutes the most vital period of life due to its essential role in cognitive, social, emotional, physical, motor development and cumulative lifelong learning (Islam et al., 2016). Improving the health of preschool children is one of the substantial objectives of healthcare services in most developing countries (Onifade et al., 2016). United Nations Children's Emergency Fund (UNICEF) estimates that approximately half of all deaths in children fewer than five years are attributable to under-nutrition (Frison et al., 2016). Nutrition is one of many elements that stimulus a child's development (Florence et al., 2008).

With two-thirds of child mortality attributable to malnutrition, Egypt stands as one of the 36 countries, where 90 percent of the global burden of malnutrition falls. The double burden of malnutrition is categorized by living of undernutrition along with overweight, obesity, or diet-related deficiencies within individuals. Children who are overweight are at risk of non-communicable diseases such as diabetes and coronary heart disease and micronutrient deficiencies due to a poor diet. The double burden of malnutrition (DBM) is a major challenge in Egypt, especially for overweight/obesity and stunting. Anemia is a disorder in which there is a deficiency of red cells or hemoglobin in the blood, resulting in paleness and fatigue; is also a major challenge in Egypt affecting 27.2 percent of children under-5. The concern about malnutrition is that it has a long series of upsetting effects on early childhood growth and development contributing not only to infant and child mortality but also, to physical, and cognitive developmental impairments among children if children survive (Ministry of Health and Population, 2015).

The relationship between nutrition and mental development and performance in children is equally important in terms of their attainment and productivity both in school and in later life (Benton, 2010). Cognitive development is influenced by the interaction between the brain and its environment (Isaacs and Oates 2008). Nutrition plays a vital role as one of the most important environmental factors influencing cognitive performance as it provides the building blocks for the neural formation and brain development (Benton, 2008).

Therefore, the objective of this study is to evaluate the nutritional status and its impact on health and cognitive development among preschool children.

\section{Subject and Methods}

Study Design: Thirty-nine healthy children of both sexes aging $53.59 \pm 1.85$ months were recruited from the urban area of Giza governorate. They were attending in nursery schools. The personal data were collected by their mothers and their ages were assessed from the birth certificates if a physical or mental disability was present or ill children at the time of the study were excluded.

\section{Data Collection and Field Work}

Data collection took place through a home visit. An informed consent form was signed by the parent before participation in the study. The study was approved by the ethical committee of the National research center with registration numbers 18-105. Anthropometric measurements were conducted on the children while the parents were being interviewed and a questionnaire was filled by the investigator on some personal 
data, socio-demographic background and 24-hour recall of their children. Subsequently, a cognitive assessment was conducted on the students one-to-one.

\section{Anthropometric measurements}

1- Age was assessed from birth certificates.

2- Body weight was assessed using a beam-type balance while the child wore very light clothes and was barefooted. This weight was taken to the nearest $0.5 \mathrm{~kg}$ (Jelliffe et al., 1989) using a kilogram weighing balances ranging from 1-130 kilograms.

3- Body height was measured to the nearest $1 \mathrm{~mm}$ for children. Height measurements were taken, while the subject was standing position against a firm wall with a fixed scale. Height was taken with no shoes and recorded to the nearest centimeter (Moussa, 1999).

4- Mid-upper arm circumference (MUAC): was measured to the nearest $0.1 \mathrm{~cm}$ with non-elastic tape over light clothing on the upper left arm. The children stood relaxed to the trained technician and the arm hanging freely at the side; the tape was passed around the arm at the level of the mid-point of the upper arm (Mazicioglu et al., 2010).

5- Body Mass Index $(\mathrm{BMI})=$ The body mass index (BMI) is the metric currently in use for defining anthropometric height/weight characteristics them into groups. It was done according to the equation weigh $(\mathrm{kg}) /$ height $^{2}(\mathrm{~m})$ (Nuttall, 2015)

\section{Dietary intake}

Triple 24-hour dietary recalls were administered to the children's mothers. Dietary data were translated into nutrient intake data using a specifically designed nutrient database, (The Egyptian Food Composition Tables and Nutrient Data Base Management System from National Nutation Institute, 2006).

\section{Cognitive Tests}

Cognitive and intellectual functioning was assessed through the application of the Wechsler Intelligence Scale for Children (WPPSI), the Arabic version (Ismaiel and Kamal, 1999).

It is designed to assess and measure the child's verbal, performance, and full- scale IQ through assessment of different functions (short- and long-term memory, comprehension, information, abstract thinking, problem-solving, and speed of information processing). Thorough application of (WPPSI), we can assess Verbal and Practical IQ as well as total IQ (Kaufman et al., 2016).

\section{Biochemical analysis:}

Blood Hemoglobin: Hemoglobin estimation was done according to Shaklai et al (1977). In a reagent solution, the ferrous ions of hemoglobin are oxidized to the ferric state by potassium ferricyanide to form methemoglobin.

Methemoglobin subsequently reacts with the cyanide ions provided by potassium cyanide to form cyanmethemoglobin.

Hemoglobin + Cyanide + Ferricyanide $\quad \longrightarrow \quad$ Cyamethemoglobin (Ion) 
The amount of cyanmethemoglobin can be measured spectrophotometrically at a wavelength of $546 \mathrm{~nm}$. The intensity of the color is directly proportional to hemoglobin concentration in the specimen.

Urinary Iodine: Urinary Iodine was determined according to (WHO, 2013). Urine samples were thawed and mixed thoroughly on a rot mixer before pipe ting. $250 \mu 1$ of urine were taken into $13 \mathrm{X} 100 \mathrm{~mm}$ scrolled test tubes then adding $1 \mathrm{ml}$ of $\mathrm{M}$ ammonium per sulfate to each tube and the samples were hydrolyzed for $1 \mathrm{~h}$ at $100^{\circ} \mathrm{C}$. After cooling the tubes to room temperature add $2.5 \mathrm{ml}$ arsenious acid solution and mix well then incubate for 15 minutes. Add $300 \mu$ l of ceric ammonium sulfate to each tube, and then incubate for 30 minutes. Readings were performed using a spectrophotometer (Thermo Fisher Scientific Genesys, USA) at $420 \mathrm{~nm}$, within 30 minutes.

\section{Statistical Analysis}

All data were expressed as the arithmetic means with standard error. Data were analyzed using SPSS Version 20.0 for Windows (Statistical Package for the Social Sciences) (Snedecor and Cochran, 1980)

\section{$\underline{\text { Results and Discussion }}$}

A suitable diet in childhood is considered to play a vital role in the physical, mental, and emotional development of children through to their later adult age. Anthropometry is a practical and immediately appropriate method for evaluating children's development patterns. Anthropometric indicators can be used as a screening device to identify individuals at risk of under-nutrition or over-nutrition, followed by a more elaborate investigation using other techniques (Rysha et al., 2017). In the present study, 39 children volunteered to assess their nutritional and cognitive status, 51\% were girls and $49 \%$ were boys. They all live in the cities of GizaGovernorate. Their ages were ranged from 57.2-71.39 months with a mean age of 53.59 \pm 1.85 months, when asking children mothers some questions about the method of delivery, birth weight, as well as breastfeeding it was found that only $26 \%$ of children were born in vaginally way and $74 \%$ in a cesarean way. $49 \%$ of children were breast feeding, $49 \%$ of children used artificial milk during infancy, 25\% were used breast feeding and $26 \%$ used both artificial and Breast feeding during infancy. Only $18 \%$ of children were playing sports. According to Meireles and Machado, (2018) were reported that a small difference was observed in cognitive performance of children born by instrumental vaginal delivery and non-planned cesarean section in comparison to those born by non-instrumental vaginal delivery or planned cesarean, nonetheless this should have a minimal impact on a child's future neurodevelopment. Borra et al., 2012 reported that breastfeeding for four weeks is positively and statistically significantly associated with higher cognitive test scores, by around one- tenth of a standard deviation In this study we measure some anthropometric measurements like weight, height, and mid-upper arm circumference (MUAC). The mean average weights of children were $16.97 \pm 0.26 \mathrm{~kg}$, the 
mean average heights of children were $101.7 \pm 0.98 \mathrm{~cm}$ so the mean average body mass index (BMI) of children were $16.47 \pm 0.21 \mathrm{~kg} / \mathrm{m}^{2}$ and MUR was $14.01 \pm 0.33 \mathrm{~cm}$. These data were shown in figures $(1,2,3$, and 4) and table (1). Cesarean section is one of the most frequently performed surgical procedures in the world, representing the most executed major obstetrical intervention, with rates varying between 5-60\%. Over the last decades, there has been a global rise in the rate of cesarean section, which is believed to have major contributors to the increase in maternal requests and changes in clinical practice. Furthermore, rates well above the World Health Organization's recommended $15 \%$ ceiling suggest a high number of unnecessary procedures.
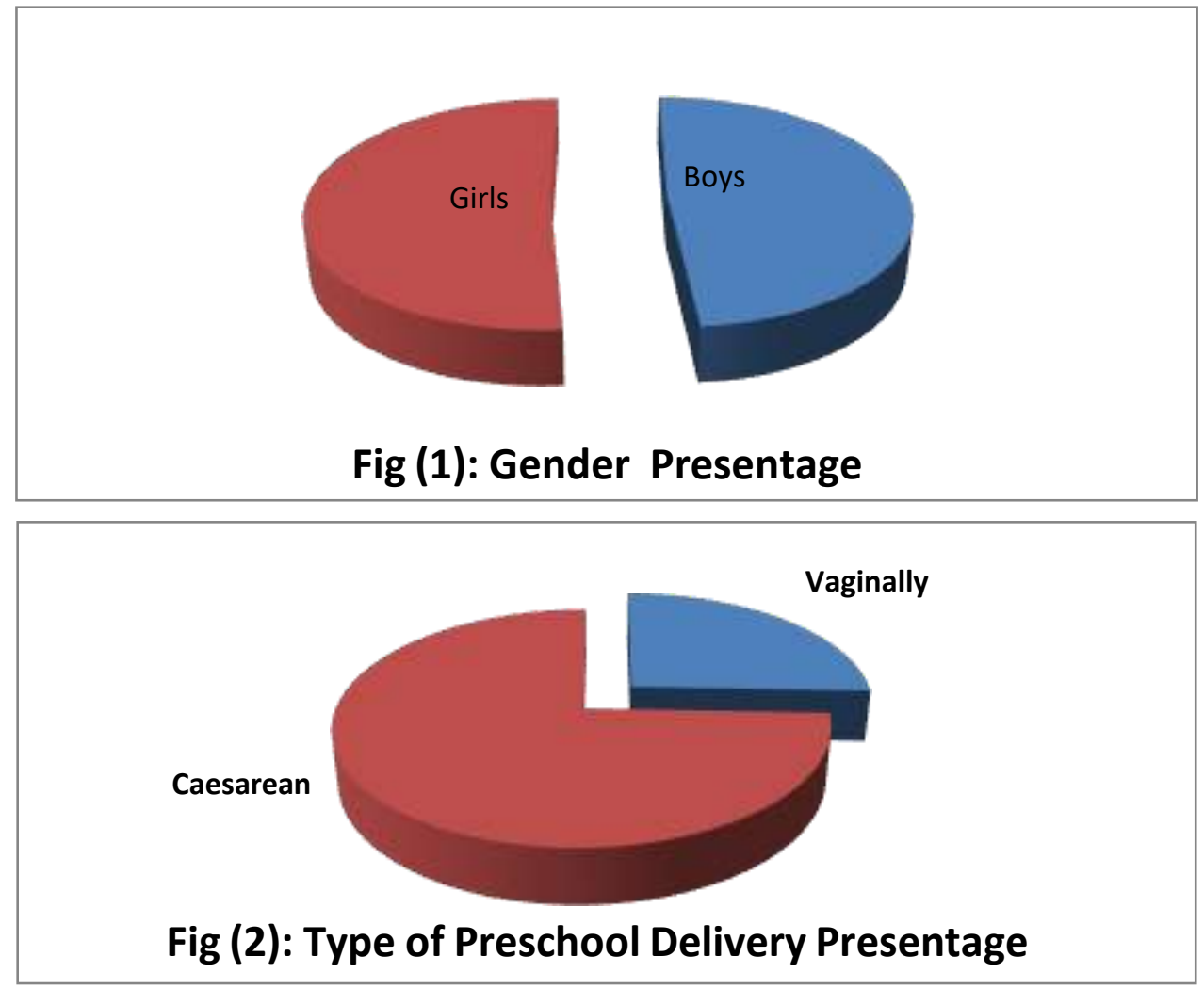

Table (1): Some Anthropometric Measurements for Preschool Children

*Body Mass Index

**Mid Upper Arm Circumference

Nutrition has a considerable in child health not only physical but also mentaland emotional. Inadequate dietary intake can cause malnutrition whether over nutrition which may cause over weight and obesity or under nutrition which may cause stunting and adverse effect on the development of the organ (Merkiel and Chalcarz, 2007). Table (2) showed the Macro Nutrient that taken by preschoolchildren that calculated from 24-hour recall 
sheets, the mean average intake from totalcalories among preschool were $985.08 \pm 32.79$

$\mathrm{Kcal} /$ day, while the mean average intake from protein was $33.74 \pm 1.12 \mathrm{~g} / \mathrm{d}$, the mean average intake from fat were $33.98 \pm 1.28 \mathrm{~g} / \mathrm{d}$ and finally, the mean average intake of total carbohydrates were $110.96 \pm 3.89 \mathrm{~g} / \mathrm{d}$.

Table (2): Total Calories and Macro Nutrient Intake among Preschool Children per day

\begin{tabular}{|l|l|l|l|l|l|l|l|l|}
\hline \multirow{2}{*}{ arameter } & nergy & & rotein & & at & \multicolumn{2}{l|}{ HO $^{*}$} \\
\cline { 2 - 10 } & $\mathbf{c a l} / \mathbf{d}$ & $b$ & d & $b$ & d & $b$ & d & $b$ \\
\hline oys & $019.302 \pm 53.50$ & 2.88 & $5.45 \pm 1.74$ & 3.74 & $4.80 \pm 2.12$ & 6.61 & $12.70 \pm 5.78$ & 6.35 \\
\hline irls & $52.56 \pm 38.76$ & 4.45 & $2.12 \pm 1.37$ & 3.46 & $3.19 \pm 1.5$ & 01.05 & $09.31 \pm 5.34$ & 9.31 \\
\hline $\begin{array}{l}\text { otal } \\
\text { hildren }\end{array}$ & $85.08 \pm 32.79$ & 3.57 & $3.74 \pm 1.12$ & 3.55 & $3.98 \pm 1.28$ & 8.68 & $10.96 \pm 3.89$ & 7.74 \\
\hline
\end{tabular}

*Carbohydrate

Several micronutrient deficiencies affect functional, particularly cognition and physical performance of children. Micronutrient deficiencies are a critical concern among children throughout the world. Approximately $30 \%$ of the world's population live in iodine-deficient areas and $25 \%$ of the world's children under age 3 y have irondeficiency anemia, with higher rates in developing countries (Black, 2003).

According to Food and Nutrition Board, Institute of Medicine, National Academies the Estimated Average Requirements (EAR) from Iodine, iron, selenium, and zinc were $65 \mu \mathrm{g} / \mathrm{d}, 4.1 \mathrm{mg} / \mathrm{d}, 23 \mu \mathrm{g} / \mathrm{d}$, and $4 \mathrm{mg} / \mathrm{d}$ respectively. In the present study, we focused on the dietary actually intake from some minerals that may be related to brain development like iodine, iron, selenium, and zinc showed in the table (3). The mean average intakes of iodine in the present study were $81.64 \pm 5.49 \mu \mathrm{g} / \mathrm{d}$ so the percentage of the actual intake among preschool children was $125.6 \%$. The mean average intake from iron among preschool student in the present study was $9.71 \pm 0.49 \mathrm{mg} / \mathrm{d}$ so the percentage of the actual intake among preschool children were $236.83 \%$. The mean average intakes from Selenium in the present study were $42.79 \pm 2.67 \mu \mathrm{g} / \mathrm{d}$ so the percentage of the actual intake among preschool children were $186.04 \%$ and finally the mean average intake from zinc among preschool student in the present study were $4.77 \pm 0.22 \mathrm{mg} / \mathrm{d}$ so the percentage of the actual intake among preschool children were $119.25 \%$.

Zinc is a cofactor for more than 200 enzymes that regulate different metabolic activities in the body, including protein and DNA synthesis. Zinc is also found in high concentrations in synaptic vesicles of hippocampal neurons, which are centrally involved in education and memorial status (Nyaradi et al., 2013).

Iron has import role for children because of its critical impact on their development. Iron is an essential role in the normal anatomical development of the fetal brain. Iron deficiency in early childhood is the most common micronutrient deficiency and can lead to irreversible damage to brain structure and cognitive function, regardless of therapies with iron supplements (Cerami, 2017). 
Iodine is a vital trace element for the function of the organism. It is essential for the biosynthesis of thyroid hormones, necessary for normal increase, development and functioning of the metabolism throughout life. Iodine deficiency can cause irreversible brain damage and mental retardation (Ghassabian and Trasande, 2018).

Selenium is a mineral that has antioxidant action. It reduces free radicals as wellas inhibits the manufacture of new ones in the organism since it is a critical element for GSH-Px, which is an enzyme with antioxidant activity. Selenium deficiency has been more associated with reduced immune system effect (innate and adaptative), precisely the activity of selenoproteins in the oxidative system that reduce the free oxygen radicals formed in the manufacture of thyroid hormones. Selenium deficiency is also related to the development of cretinism since it presents a direct relation with iodine in the organism during hormone conversion (Ventura et al., 2017).

Table (3): Minerals Intake among Preschool Children Per day

\begin{tabular}{|c|c|c|c|c|c|c|c|c|}
\hline \multirow{2}{*}{ arameters } & \multicolumn{2}{|l|}{ dine } & \multicolumn{2}{|l|}{ on } & \multicolumn{2}{|l|}{ lenium } & \multicolumn{2}{|l|}{ inc } \\
\hline & $\mathrm{g} / \mathrm{d}$ & & $g / d$ & p & $\mathrm{s} / \mathbf{d}$ & & $\mathrm{g} / \mathrm{d}$ & \\
\hline bys & $15.74 \pm 9.71$ & 9.47 & $75 \pm 0.84$ & $\beta 7.88$ & $.95 \pm 4.02$ & 5.43 & $04 \pm 0.34$ & 35.89 \\
\hline irls & $5.43 \pm 7.6$ & $\$ 1.44$ & $66 \pm 0.53$ & $\beta 5.61$ & $.74 \pm 3.58$ & 7.15 & $51 \pm 0.29$ & 2.78 \\
\hline Total children & $.64 \pm 5.49$ & 5.6 & $71 \pm 0.49$ & $\beta 6.83$ & $.79 \pm 2.67$ & $\beta 6.04$ & $77 \pm 0.22$ & 9.25 \\
\hline
\end{tabular}

Vitamins as essential nutrients inevitably play a role in the initial developmentof the brain, and as co-enzymes influence metabolism throughout life (Benton, 2012). According to Food and Nutrition Board, Institute of Medicine, National Academies the Estimated Average Requirements for vitamin A, B1, B2, and C were 275 IU, $0.5 \mathrm{mg} / \mathrm{d}, 0.5 \mathrm{mg} / \mathrm{d}$, and $22 \mathrm{mg} / \mathrm{d}$ respectively. Table (4) showed that the dietary actually intake from some vitamins.

The mean average intake from Vitamin A among preschool students in the present study was $273.23 \pm 25.57 \mathrm{IU} / \mathrm{d}$ so the percentage of the actual intake among preschool children was $99.27 \%$. The mean average intake from Vitamin B1 among preschool students in the present study was $0.45 \pm 0.06 \mathrm{mg} / \mathrm{d}$ so the percentage of the actual intake among preschool children was $90 \%$. The mean average intake from Vitamin B2 among preschool students in the present study was $0.49 \pm 0.03 \mathrm{mg} / \mathrm{d}$ so the percentage of the actual intake among preschool children was $98 \%$. The mean average intake from Vitamin C among preschool student in the present study was $17.01 \pm 1.14 \mathrm{mg} / \mathrm{d}$ so the percentage of the actual intake among preschool children were $77.32 \%$.

Vitamin A deficiency was also connected to iron deficiency anemia, a risk factor for cognitive impairment. Epidemiological evidence from observational studies thus far suggests that those antioxidants in the diet, supplements, and serum may play a neuroprotective role (Park et al., 2018). B-vitamins, including thiamine, is vital for 
brain development and function through many mechanisms. They play a role in carbohydrate metabolism (which helps to provide the brain's energy supply), membrane structure and function, and synapse formation and function. Neurological symptoms typically characterize thiamine-deficiency disorders. In high-income countries, thiamine deficiency in infants has become a rare condition since food has been enriched with thiamine (Butterworth, 2003). Increasing proofs suggested that vitamin $\mathrm{C}$ has vital redox homeostatic factor in the central nervous system, relating to a poor dietary intake of Vitamin $\mathrm{C}$ to adverse effects on cognitive performance (Tveden-Nyborg and Lykkesfeldt, 2009). Several in vitro and in vivo experiments have supported an essential role for Vitamin $\mathrm{C}$ in the brain, both as a powerful antioxidant and scavenger of ROS, as well as a key factor in the recycling of other brain antioxidants (Lykkesfeldt et al., 2007).

Table (4): Vitamins Intake among Preschool Children Per day

\begin{tabular}{|c|c|c|c|c|c|c|c|c|}
\hline \multirow{2}{*}{ Parameters } & \multicolumn{2}{|l|}{ Vitamin A } & \multicolumn{2}{c|}{ Vitamin B1 } & \multicolumn{2}{c|}{ Vitamin B2 } & \multicolumn{2}{c|}{ Vitamin C } \\
\cline { 2 - 9 } & IU & $\boldsymbol{\%}$ & $\mathbf{m g}$ & $\boldsymbol{\%}$ & $\mathbf{m g}$ & $\boldsymbol{\%}$ & $\mathbf{m g}$ & \% \\
\hline \multirow{2}{*}{ Boys } & $268.29 \pm 25.73$ & 97.58 & $0.52 \pm 0.12$ & 104.32 & $0.49 \pm 0.04$ & 97.85 & $6.84 \pm 1.64$ & 76.54 \\
\hline Girls & $277.94 \pm 44.19$ & 101.07 & $0.39 \pm 0.05$ & 78.15 & $0.49 \pm 0.04$ & 98.7 & $17.18 \pm 1.63$ & 78.07 \\
\hline Total Children & $273.23 \pm 25.57$ & 99.27 & $0.45 \pm 0.06$ & 90 & $0.49 \pm 0.03$ & 98 & $17.01 \pm 1.14$ & 77.32 \\
\hline
\end{tabular}

The laboratory analysis used in the biochemical tests is shown in table (5). The results show that the mean averages of urinary iodine were $159.55 \pm 3.08 \mu \mathrm{g} / \mathrm{L}$, however the blood taken from children was used for hemoglobin analysis. The results show that the mean average blood hemoglobin was $11.5 \pm 0.10 \mathrm{~g} / \mathrm{dl}$. Its notice that there is no iodine deficiency or anemia among the preschool children, these results reflect the intake of food, especially iron and iodine. Abdel-Rasoul et al., 2017 prevalence of iron deficiency anemia among preschool children was 52.2\%., and higher in girls than in boys but did not reach a significant level. Elsayed et al., 2015 reported that iodine deficiency (ID) $(<100 \mu \mathrm{g} / \mathrm{L})$ is present among $10 \%$ of the studied primary school children in seven governorates but there is no accurate data about iodine deficiency in preschool children in Egypt Table (5): Some Biochemical Analysis of Preschool Children

\begin{tabular}{|c|l|l|l|}
\hline Biochemical & Boys & Girls & Total Children \\
\hline Urinary lodine & $156.32 \pm 4.25$ & $162.63 \pm 4.45$ & $159.55 \pm 3.08$ \\
\hline Blood Hemoglobin & $11.63 \pm 0.15$ & $11.38 \pm 0.13$ & $11.5 \pm 0.10$ \\
\hline
\end{tabular}


The Wechsler IQ (WPPSI) tests for preschool children are the most frequently used individual IQ test used worldwide. These tests convert to scores that express the IQ of children. IQ results among the children in our study showed in table (6). This study showed that the Verbal IQ of children was $98.43 \pm 0.99$, the performance IQ of children was $76.23 \pm 2.78$ and the total IQ was $94.61 \pm 0.93$. The results of IQ tests showed a normal range average in children's IQ (the average ranges were 90-109). From the previous results, it's childhood, while a healthy diet, associated with high intakes of nutrient-rich foods described normal to the children in the study to have a good IQ result. Northstone et al., 2012 demonstrated that unhealthy or inadequate diet associated with high fat, sugar, and processed food content in early childhood may be associated with small reductions in IQ in later at about the time of IQ assessment may be associated with small increases in IQ.

Table (6): IQ Scale among Preschool Children

\begin{tabular}{|l|l|l|l|}
\hline Parameter & Boys & Girls & Total \\
\hline Verbal IQ & $103.74 \pm 1.68$ & $102.75 \pm 1.69$ & $103.23 \pm 1.18$ \\
\hline Performance IQ & $76.21 \pm 4.28$ & $76.25 \pm 3.68$ & $76.23 \pm 2.78$ \\
\hline Total IQ & $95.47 \pm 1.52$ & $93.8 \pm 1.14$ & $94.61 \pm 0.93$ \\
\hline
\end{tabular}

\section{Conclusion:}

Big attention to proper nutrition for children has become of great interest to the Egyptian government. From the previous data, it was noted that the nutritional status in childhood and the cognitive performance of pre-school children in the present studyneeds further follow-up and data to know the level of the expected impact on the health and cognitive status for preschool children.

\section{References:}

Abdel-Rasoul G. M., Elgendy F. M. and Mostafa L. A. (2017): Iron deficiency anemia among preschool children (2-6 years) in a slum area (Alexandria, Egypt): an intervention study. Menoufia Medical Journal. 30(1):213-220

Benton D. (2008): The influence of children's diet on their cognition and behavior. European Journal of Nutrition. 47(3): 25-37

Benton D. (2010): The influence of dietary status on the cognitive performance of children. Molecular Nutrition and Food Research. 54:457-470.

Benton, D. (2012): Vitamins and neural and cognitive developmental outcomes in children. Proceedings of the Nutrition Societ.71(1):14-26.

Black M. M. (2003): Micronutrient Deficiencies and Cognitive Functioning. The Journal of Nutrition.133(11): 3927S-3931S. 
Borra C., Iacovou M. and Sevilla A. (2012): The effect of breastfeeding on children's cognitive and non-cognitive development. Labour Economics. 19(4):496515

Butterworth R.F. (2003): Thiamin deficiency and brain disorders. Nutrition Research Reviews. 16:277-283

Cerami, C. (2017): Iron Nutriture of the Fetus, Neonate, Infant, and Child. Annals of Nutrition and Metabolism. 71(3): 8-14.

Elsayed H.H., Abd El-Rahman M. K. and Tawwfik A.A. (2015): Iodine Status of Primary School Children in Different Egyptian Environments. The Egyptian Journal of Hospital Medicine.61: 451- 458.

Florence M. D., Asbridge M. and Veugelers P. J. (2008): Diet Quality and Academic Performance/. Journal of School Health. 78(4):209-215.

Frison S., Kerac M., Checchi F. and Prudhon C. (2016): Anthropometric indices and measures to assess change in the nutritional status of a population: a systematic literature review BMC Nutrition.2:76

Ghassabian A. and Trasande L. (2018): Disruption in Thyroid Signaling Pathway: A Mechanism for the Effect of Endocrine-Disrupting Chemicals on Child Neurodevelopment. Fronties in Endocrinology (Lausanne). 9:204.

Isaacs E. and Oates J. (2008): Nutrition and cognition. Assessing cognitive abilities in children and young people. European Journal of Nutrition;47(3): 4-24.

Islam M. T., Rashid F. and Hossain S. A. (2016): Early Childhood Care and Development: An Investigation into a Day Care Center in Bangladesh. American Journal of Educational Research. 4(4): 338-346

Ismaiel E. and Kamal M. (1999): Wechsler intelligence scale for children revised, Arabic version, 7th edn. El-Nahda El Massryia, Cairo

Jelliffe D. P., Jelliffe E. F. P., Zerfas A. and Neumann G. G. (1989): Community nutrition assessment. Oxford university pree. Oxford New York.

Kaufman, Alan S; EngiRaiford, Susan and Coalson, Diane L. (2016): Intelligent testing with WISC-V. Hoboken, New Jerset; John Wiley \&Son.p237.ISBN978- 1-11858923-6.

Lykkesfeldt J., Trueba G.P., Poulsen H.E. and Christen S. (2007): Vitamin C deficiency in weanling guinea pigs: Differential expression of oxidative stress and DNA repair in liver and brain. British Journal of Nutrition . 98, 1116-1119

Mazicioglu M. M., Hatipoğlu N., Oztürk A. and Kurtoğlu S. (2010): Waist circumference and mid-upper arm circumference in evaluation of obesity in children aged between 6 and 17 years. Journal Of Clinical Research In Pediatric Endocrinology. 2(4): 44-50 
Meireles J. P. and Machado H.S. (2018): The Influence of Mode of Delivery on the Neurodevelopment of Children and Adolescents. Journal of Pregnancy and Child Health.5 (3):

Merkiel S. and Chalcarz W. (2007): Nutrition in preschool age: Part 1. Importance, reference values, methods of research and their application. Review. Clinical observation journal.68-73

Ministry of Health and Population (2015): Egypt Health Issues Survey (EHIS). In collaboration with: El Zanaty and Associates, USAID, UNFPA and UNICEF.

Moussa W. (1999): Assessment of Nutritional Status of the individual and the community. 6th Regional training course in Nutrition Institute, Cairo, Egypt

Northstone K., Joinson C., Emmett P., Ness A. and Paus T. (2012): Are dietary patterns in childhood associated with IQ at 8 years of age? A population-based cohort study. J Epidemiol Community Health.66 (7):624-8

Nyaradi, A., Li, J., Hickling, S., Foster, J. \& Oddy, W.H. (2013): The role of nutrition in children's neurocognitive development, from pregnancy through childhood. Frontiers in Human Neuroscience, 7:97.

Nuttall F (2015): Body Mass Index. Nutrition Today 50(3):1

Onifade O.M., Otegbayo J. A., Akinyemi J.O., Oyedele T. A. and kinlade A.R. (2016): Nutritional status as a determinant of cognitive development among preschool children in South-Western Nigeria. British Food Journal. 118 (7): 1554-1567

Park S., Kim H.K., Myung W., Yoo J.H., Shin S.J., Na D.L, Kim S.Y., Lee J.-H., Kim S.Y. and Han S.H.(2018): Risk Factors of Behavioral and Psychological Symptoms in Patients with Alzheimer Disease: The Clinical Research of Dementia of South Korea Study. Korean Fam Community Med. 40, 16-21.

Rysha A. , Gjergji T.M. and Ploeger A. (2017): Nutritional status of preschool children attending kindergartens in Kosovo Journal of Health, Population and Nutrition.36(26).

Shaklai N, Yguerabide J, and. Ranney H (1977): Interaction of hemoglobin with red blood cell membranes as shown by a fluorescent chromophore. Biochemistry.16(25): 5585-5592

Snedecor, G.W. and Cochran, W.G. (1980). Statistical Methods. Seventh Edition. Ames Iowa: The Iowa State University Press.

Tveden-Nyborg, P. and Lykkesfeldt, J. (2009): Does vitamin C deficiency result in impaired brain development in infants? Redox Rep. 14, 1-6

Ventura, M.; Melo, M.; Carrilho, F. (2017): Selenium and thyroid disease: From pathophysiology to treatment. International Journal of Endocrinolog. 12 (9):76- 88

World Health Organization (WHO) (2013): Urinary iodine concentrations for determining iodine status deficiency in populations. Vitamin and Mineral Nutrition Information System. Geneva: World Health Organization 